\title{
Plan de reconstrucción nacional, su impacto en la economía nacional 1992-19931
}

\author{
Aida Celia Argüello Romero \\ Ricardo Miguel Granillo Funes
}

\begin{abstract}
El Plan de Reconstrucción Nacional (PRN) es un conjunto de proyectos y programas que nace con los acuerdos finales de paz firmados por el gobierno de ARENA y el FMLN el 16 de enero de 1992 en la ciudad de México. Este plan forma parte de la plataforma mínima de compromisos dentro del tema económico y social de dichos acuerdos (Capltulo V) y se configura como un deber jurídico que exige estabilidad económica, social y política como requisito para alcanzar la paz y reconciliación de todos los sectores del país. Al mismo tiempo, la ejecución y cumplimiento de los objetivos del PRN son un elemento clave para el logro de la paz. Es decir, el conjunto de acuerdos de paz conforma el verdadero PRN y el cumplimiento de todos los compromisos sentarla las bases para mejorar la situación de pobreza e inequidad que predomina en la mayor parte de la población salvadoreña.

El estudio del impacto económico del PRN muestra la posible influencia de éste en el objetivo general del programa de estabilización y ajuste
\end{abstract}

1. Este artículo es una síntesis de nuestra tesis de graduación "Plan de reconstrucción nacional su impacto en la economla nacional 19921993", de la cual se han omitido algunas partes por razones de espacio. Los interesados en ampliar la información que aqul se presenta pueden consultar la tesis mencionada. 
estructural, que es lograr el desarrollo económico y social de la nación. Sin embargo, dado el poco tiempo transcurrido desde el inicio de la implementación del PRN, no podemos determinar su impacto a través de variables macroeconómicas, pero sl se puede analizar su compatibilidad con el actual plan de desarrollo y cuál es el impacto que han ejercido los proyectos de reconstrucción sobre la economia en general. La compatibilidad de ambos planes se ha determinado a través de la integración de sus principios filosóficos, postulados económicos y sociales, objetivos y estrategias; y el impacto de los proyectos se percibe a través de las apreciaciones hechas por diferentes actores y beneficiarios del mismo.

Este análisis permite determinar si el PRN está sentando las bases necesarias para fortalecer el proceso de reconciliación y pacificación a través de cambios económicos y sociales profundos, con los cuales se logre alcanzar el crecimiento con equidad que necesita el pais.

Se pretende establecer cómo los objetivos del PRN pueden influir en los objelivos del Plan de Desarrollo Económico y Social 1989-1994 y de qué forma se integrarán ambos planes, pues el plan de desarrollo no es tema de discusión, conforme lo planteado en el Acuerdo de Paz. Por lo tanto, el PRN debe buscar una transformación productiva que permita lograr el crecimiento con equidad, pero condicionado por un programa de desarrollo que restringe la demanda de quienes históricamente no han tenido capacidad de demandar.

De acuerdo a su título "Plan de Reconstrucción Nacional", cabe preguntarse cuál es su verdadero alcance. En primer lugar, se centra únicamente en los municipios más golpeados por la guerra y en segundo lugar, esta zona ha sido tradicionalmente la más pobre y marginada de todo tipo de actividad pública y privada. Entonces, ¿es un plan nacional o regional? ¿se trala de construcción o reconstrucción? Se trata de construcción en aquellas zonas donde no existía acción del Estado ni del sector privado, y es reconstrucción en las zonas donde la infraestructura existente fue dañada por el conflicto. Pero sobre todo se trata de reconstrucción por razones políticas, es decir para efectos de imagen internacional que permitiera obtener financiamiento para reconstrucción de posiguerra y no construcción y abastecimiento de necesidades insatisfechas aún antes de la guerra. Por otra parte y a pesar que el plan se centra en una zona específica del pais, es nacional en el sentido de la variedad de sus participantes y de los aportes que ha generado a nivel de cambios en la visión de luturas políticas para el desarrollo de la nación.

Desde un punto de visla económico, el PRN busca crear y restaurar 
la infraestructura básica necesaria para el desarrollo social y productivo de su zona y población objetivo. Además, pretende satisfacer las necesidades sociales básicas de dicha población y fomentar la concertación, reconciliación y pacificación; indicando que no sólo se trata de determinar el impacto del PRN sobre variables meramente económicas como la inflación, inversión, ahorro, déficit, sino también señalar los logros sociales.

Un aspecto interesante y novedoso del PRN es que en su implementación se unifican acciones y objetivos de sectores con principios distintos y hasta contrarios; integrándose, a pesar de las dificultades, el Gobierno de El Salvador, el FMLN, Organismos no Gubernamentales e Internacionales y las comunidades, con el único fin de contribuir con la reconstrucción del país.

A pesar que el Plan de Reconstrucción es un elemento importante en el proceso de paz, el hecho de que su implementación dependa básicamente de recursos externos pone en peligro y hace vulnerable su ejecución y mantenimiento de las obras ya realizadas. Además su ubicación temporal en un período preelectoral da lugar a que se interprete como un medio que va a permitir ganar influencia política donde no se tenía por causa de la guerra.

De acuerdo a lo planteado anteriormente, este trabajo se desarrolla de la siguiente manera. En la primera parte hacemos una exposición breve de los antecedentes del Plan de Reconstrucción. En la segunda parte se presenta el enfoque teórico que utilizamos para hacer el análisis del impacto del PRN en la economía nacional. Este es el planteamiento de la CEPAL denominado Equidad y Transformación Productiva, un Enfoque Integrado. La tercera parte consiste en la descripción del PRN y sus elementos. En la cuarta parte realizamos un análisis de la integración del PRN al actual plan de desarrollo, el PRN en el marco teórico de equidad y transformación productiva y la presentación de los resultados obtenidos de las diferentes entrevistas realizadas a instituciones relacionadas con la implementación de este plan y con las comunidades beneficiarias. Finalmente exponemos las conclusiones a las que llegamos en la investigación.

\section{ANTECEDENTES}

El antecedente inmediato del PRN es el Acuerdo de Paz firmado en Chapultepec, donde aparece como uno de los temas de discusión y concertación entre el Gobierno de El Salvador y el FMLN. Pero en la Proclama de la Fuerza Armada de 1979 se observa que los elementos 
que fueron parte causal del conflicto armado desatado en esa época coinciden con varios elementos que se presentan en la actualidad en los acuerdos de paz: derechos humanos, corrupción, pobreza, elecciones libres, etc. Esta proclama resume la historia de la guerra, considerando los hechos económicos, pollticos y sociales que llevaron a la necesidad de implementar el Plan de Reconstrucción Nacional.

Otros antecedentes son los planes que ya se estaban ejecutando cuando se inició el PRN y que pueden ver afectados sus objetivos debido a la aplicación simultánea de los distintos planes. Este es el caso del Plan de Desarrollo Económico y Social 1989-1994 y el Programa Básico de Inversiones. Es decir, que cualquier otra política económica o social que se quiera aplicar simultáneamente podría afectar el actual modelo, positiva o negalivamente, al grado de profundizar ciertos desequilibrios micro o macroeconómicos. El Plan de Desarrollo es un plan de rescate macroeconómico y el Programa Básico de Inversiones busca compensar y minimizar el impacto de los programas de ajuste estructural sobre los sectores más desposeldos, elevando el nivel de inversión pública.

\section{MARCO TEORICO}

Dada la dificultad de seguir ignorando la gravedad de los problemas sociales: profundización de la pobreza, mayor concentración de la riqueza y de los frutos del crecimiento, deterioro continuo de la condiciones de salud, nutrición, educación, etc., el Banco Interamericano de Desarrollo (BID), la Comisión Económica para América Latina y el Caribe (CEPAL) $\Theta$ incluso la nueva orientación económica de los Estados Unidos han reconocido la necesidad de darle prioridad a la política social, y especialmente a la pobreza, en los palses de América Latina. Han relomado como puntos de interés los debates relacionados con la tesis de crecimiento con equidad, dejando de lado los supuestos neoliberales del efecto "goteo" en la distribución del crecimiento.

Considerando las nuevas circunstancias, se ha tomado como base teórica para este estudio el enfoque propuesto por la secretarla de la CEPAL como solución a la problemática del desarrollo en los países de América Latina y el Caribe. Esle planteamiento consiste en lograr integrar simultáneamente la política económica y social, de tal manera que permila obtener un cierto grado de crecimiento económico, y a la vez, mejorar al máximo las condiciones de vida de cada uno de los miembros de la población. En general, se persigue minimizar la pobreza económica, política y social; un desarrollo humano integral, sin privilegios ni discriminaciones y desarrollar latentos para tener oportunidades iguales de 
toda índole; y lograr una distribución justa del poder y la riqueza.

Este enfoque integrado nos proporciona una perspectiva de las articulaciones que deben existir entre ciertos aspectos claves de análisis y políticas que permitan lograr, simultáneamente, un mayor crecimiento y equidad. Es decir, potenciar las complemetariedades entre las acciones que buscan mayor crecimiento y equidad, prefiriendo las politicas económicas que favorecen el crecimiento y la equidad y las políticas sociales que promuevan el efecto productivo, la eficiencia y la equidad. De tal manera que ambos objetivos avancen en forma simultánea y no secuencial o separada.

Según la CEPAL no sólo es deseable sino también posible un crecimiento con equidad, ambientalmente sustentable y en democracia. Las llaves para lograrlo son:

a) creación de empleo productivo que proporcione igualación de oportunidades a toda la población;

b) transformación productiva sustentada en la incorporación deliberada y sistemática de progreso técnico; y

c) una adecuada y eficiente inversión en recursos humanos. Específicamente lo que se refiere a capacitación y educación de la población, tomándolo como elemento pivote para el progreso técnico. La CEPAL recomienda mejorar la calidad de la educación y asegurar a todos los estratos sociales un acceso similar a ésta. Sin embargo, para lograrlo es necesario redefinir la política del gasto social, de manera que de lugar a una eficiente asignación de los servicios orienlados a satisfacer las necesidades básicas, y reformar el papel del Estado a nivel central y regional, para que permita a las organizaciones de la sociedad civil ejecutar algunos proyectos.

Este enfoque coincide con los planteamientos de Richard Jacob en cuanto a la simultaneidad del crecimiento con equidad y la indisolubilidad de las relaciones entre la política económica y la polílica social: "El Estado, la economia y la sociedad deben y pueden ordenarse de tal manera que ambos fines, el de crecimiento y el de distribución, no se contradigan sino que se complementen, o sea que se condicionan mutuamente. ${ }^{n_{2}}$

2. Jacob, Richard, "Política social en la economia social de mercado. ¿qué signilica "social" en el concepto de economía social de mercado? en Contribuciones $3 / 92$. 


\section{DESCRIPCIÓN DEL PRN}

El gobierno de El Salvador fue el primero en exponer la idea de la reconstrucción nacional, ante la posibilidad del cese al enfrentamiento armado. En mayo de 1991 presentó en el primer Grupo Consultivo convocado por el Banco Internacional de Reconstrucción y Fomento (BIRF), la propuesta preliminar de este documento.

El Plan de Reconstrucción Nacional no es un documento definitivo pues permite incorporar cambios en la medida que se avance en el levantamiento de información más concreta sobre la situación real de los territorios que incluye; también está sujeto a ajustes que surjan de los acuerdos definidos por la dinámica del proceso de negociación y la incorporación de iniciativas derivadas de la concertación. Por ejemplo, a partir de la firma de los acuerdos de paz, el FMLN entró a participar en el análisis del trabajo realizado por el GOES. Desde el 14 de febrero de 1992 se comenzaron a debatir y readecuar los planteamientos para lograr un nivel de consenso entre ambas partes, especialmente en el programa que concierne al apoyo de desmovilizados.

\section{A. ESTRUCTURA DEL PRN}

A.1) Objetivos. El objetivo central del PRN es la creación de condiciones de armonla que faciliten la unidad nacional, mediante el establecimiento de las bases que fortalezcan el proceso de reconciliación y la creación de las condiciones económicas y sociales para la reintegración de los miembros de la sociedad mayormente afectados por el conflicto.

Los objetivos especificos son:

- facilitar la reintegración a la vida civil y productiva de los excombatientes y de la población mayormente afectada por el conflicto;

- mejorar las condiciones sociales, económicas y ambientales de las áreas geográficas mayormente afectadas por el conflicto;

- reconstruir la infraestructura básica, social y productiva dañada o destruida durante el conflicto; y

- promover la participación solidaria de todos los seclores de la vida nacional en el esfuerzo de la reconstrucción nacional. ${ }^{3}$

Para coordinar la implementación, el desarrollo y cumplimiento de estos objetivos fue creada la Secretarla de Reconstrucción Nacional, que depende directamente de la Presidencia de la República.

3. MIPLAN, Plan de Reconstrucción Nacional (PRN), marzo 1992. 
A.2) Población y territorios objetivo. La población beneficiaria de este plan son:

- los demovilizados de la Fuerza Armada (45,362 personas) y del FMLN (10,994 personas);

- los desplazados (60,000 personas);

- repatriados bajo el amparo de ACNUR (26,000 personas); y

- la población ubicada en las zonas más afectadas por el conflicto residentes en los territorios objetivo ( $1,645,756$ personas).

Totalizando una cantidad de $1,788,112$ beneficiarios que representan aproximadamente el $32 \%$ de la población total.

EI PRN define como territorios objetivo a 115 municipios más afectados por el conflicto, situados en la zona norte del pals y las zonas geográficas determinadas en función de la localización de los proyectos de rehabilitación y/o reconstrucción de la intraestructura dañada, que significa una cobertura geográfica del $40 \%$ del territorio nacional.

A.3) Modalidades de participación para la ejecución de proyectos. " Si bien es cirto que que el PRN persigue mejorar y ampliar la presencia de las instiluciones del Estado, también prevé mecanismos para ampliar la participación de la sociedad civil: las organizaciones no gubernamentales. asociaciones comunitarias y sector privado, a fin de desarrollar nuevas formas de relación entre el Estado, intituciones privadas y la comunidad, con el fin de acercarse a la población, no sólo para prestarle servicios sino también para facilitar el proceso de reconciliación y de solidaridad.4

Para fortalecer la participación de las comunidades se crearon los Cabildos Abiertos Ampliados que propician la concertación y coordinación entre el gobierno local, la Secretaría de Reconstrucción, los ejecutores y las comunidades beneficiarias en lo relacionado con los proyectos de cada localidad.

Por otra parte, los mecanismos de participación de las ONG en la ejecución de los proyectos dentro del PRN son a través de:

- contrato directo con la SRN;

- contrato con las municipalidades;

- contrato con las instituciones públicas; y

- contrato con otra ONG.

4. MIPLAN, PRN, marzo 1992, pág. 11. 
En general, las opciones de participación e incorporación de los distintos actores para la realización de proyectos y programas de reconstrucción son:

- que los gobiemos locales ejecuten directamente proyectos identificados en los Cabildos Abiertos Ampliados;

- los alcaldes y la SRN pueden subcontratar y contratar, respectivamente a instituciones del sector público, privado y ONG;

- el FIS y las instituciones públicas podrán subcontratar a instituciones privadas, ONG o asociaciones comunitarias; y

- las instituciones del sector público, ONG y asociaciones comunitarias podrán ejecutar directamente proyectos con previa aprobación de la SRN.

A.4) Fases de implementación y programas. El PRN distingue dos fases para su realización: la Fase 1 o de Contingencia que comprende programas y acciones considerados como más urgentes, prioritarios y factibles de ejecutar inmediatamente después del cese de fuego. Está limitada por la disponibilidad de recursos e incluye proyectos que deberán iniciarse en un periodo no mayor de seis meses. La Fase II o de Mediano Plazo comprende programas y proyectos esenciales para proporcionar atención a las necesidades básicas en el perlodo de reintegración económica y social y aquellos programas que fortalezcan su recuperción. Esta fase requiere de un perfodo de tiempo más amplio, aproximadamente 5 años. Las estimaciones de los requerimientos financieros de ambas fases y sus proyectos se pueden observar on los cuadros 1 y 2.

\section{B. PROYECTOS REALIzADOS}

Las fases de contingencia y de mediano plazo que comprende el PRN están enmarcadas en cuatro programas: infraestructura básica, desarrollo social y productivo, apoyo a la reinserción de desmovilizados, administración y programa de alimentos. En la fase de contingencia, concluída en diciembre de 1992 , se ejecutaron 8,418 proyectos con un valor total de 230.16 millones (US $\$ 27.08$ millones) y un costo promedio por proyecto de $₫ 27,341$. Para esta etapa el gobierno habia estimado realizar obras por un valor de $\$ 443.58$ millones que no fueron concretados por diversas razones, entre las cuales figuran la falta de fondos, problemas de organización y otras dificultades.

Dentro de la fase II se han asignado US\$ 74.2 millones, de los 


\begin{tabular}{|c|c|c|}
\hline $\begin{array}{r}\text { CUADRO } 1 \\
\text { PROGRAMA DE RECONSTRUCCIC } \\
\text { FASE DE CONTINGENC } \\
\text { (MILLONES DE COLON }\end{array}$ & $\begin{array}{l}\text { NACIONAL } \\
\text { S) }\end{array}$ & \\
\hline COMPONENTES & $\begin{array}{l}\text { UNIDAD } \\
\text { EJECUTORA }\end{array}$ & TOTAL \\
\hline A. CON RECURSOS NUEVOS & & 116.56 \\
\hline $\begin{array}{l}\text { 1. Coordinación Proyeclos PRN } \\
\text { Perfiles Sociodemográficos } \\
\text { Apoyo Documentación } \\
\text { Administración } \\
\text { 2. Rehabililación Económica y Social Básica }\end{array}$ & $\begin{array}{l}\text { SRNFUNDASALVA } \\
\text { SRN/ALCALDIAS } \\
\text { SRN }\end{array}$ & $\begin{array}{r}7.51 \\
0.80 \\
0.70 \\
6.01 \\
84.30\end{array}$ \\
\hline $\begin{array}{l}\text { Reconstrucción Infraest4ruclura Básica } \\
\text { Salud, Educación y Proyectos Productivos } \\
\text { 3. Capacitación y Educación }\end{array}$ & $\begin{array}{l}\text { SRN/ALCALDIAS } \\
\text { ONG'S }\end{array}$ & $\begin{array}{l}59.30 \\
25.00 \\
12.00\end{array}$ \\
\hline $\begin{array}{l}\text { Capacilación Privada Corto Plazo } \\
\text { Contratación Temporal Educadores }\end{array}$ & $\begin{array}{l}\text { SRN/ONG's } \\
\text { MINEDUC }\end{array}$ & \\
\hline $\begin{array}{l}\text { 4. Fondo de Reserva } \\
\text { Fortalecimiento Institucional } \\
\text { Fortalecimiento Institucional } \\
\text { Otros }\end{array}$ & $\begin{array}{c}\text { ISTA } \\
\text { Banco de Tierras }\end{array}$ & $\begin{array}{r}12.75 \\
6.15 \\
0.23 \\
6.37\end{array}$ \\
\hline B. CON RECURSOS PROPIOS DE INSTITUCIONES & & 327.02 \\
\hline $\begin{array}{l}\text { 1. Habilitación de los servicios de Salud } \\
\text { 2. Vacunación de nlños } \\
\text { 3. Rehabilitación de Discapacitados } \\
\text { 4. Acreditación de Niveles Educativos y Laborales } \\
\text { 5. Diagnóstico Infraestructura Escolar } \\
\text { 6. Rehabilitación de Carreteras Terciarias y Rurales } \\
\text { 7. Educación Ambienlal para Relorestación } \\
\text { 8. Manejo de deshechos Sólidos en Centros Urbanos }\end{array}$ & $\begin{array}{l}\text { MSPAS } \\
\text { MSPAS } \\
\text { FUNTER } \\
\text { MINEDUC } \\
\text { MINEDUC } \\
\text { MOP } \\
\text { SEMA } \\
\text { SEMA }\end{array}$ & $\begin{array}{r}3.00 \\
0.60 \\
8.64 \\
0.20 \\
0.80 \\
15.00 \\
0.52 \\
0.24\end{array}$ \\
\hline $\begin{array}{l}\text { 9. Eslablecimientos de Criterios para evaluar el } \\
\text { Impacto Ambiental del PRN } \\
\text { 10. Análisis Impacto Ambiental y Planificación de }\end{array}$ & SEMA & 0.01 \\
\hline $\begin{array}{l}\text { Reasentamientos Post-Conflictos } \\
\text { 11. Adquisición de Tierras }\end{array}$ & SEMA & 0.01 \\
\hline $\mathrm{ESF} / 90$ & Banco de Tierras & 18. \\
\hline ESF/91 & Banco de Tierras & 75.00 \\
\hline $\begin{array}{l}\left.\text { 12. Adquisición de Tierras (Bonos serie " } \mathrm{C}^{n}\right)^{2} \\
\text { 13. Translerencia de } 3,000 \text { manzanas del Estado }\end{array}$ & $\begin{array}{l}\text { ISTA } \\
\text { GOES }\end{array}$ & $\begin{array}{r}175.00 \\
30.00\end{array}$ \\
\hline TOTAL & & 443.58 \\
\hline
\end{tabular}

1. Ha ser ejecutado en 1992

2. Emisión de bonos previsla en la Ley Básica de la Relorma Agraria 


\section{CUADRO 2 \\ INVERSION ESTIMADA PARA 5 AÑOS EN LA FASE DE MEDIANO PLAZO PLAN DE RECONSTRUCCION NACIONAL}

\section{SECTOAES Y PAOYECTOS}

A. SECTOR SOCIAL Y NECESIDADES DE CAPTILL HUUANO

1. Rehabilifación de Discapacidades Fisicas y Sensorlales

2. Desarrollo de la Educaclón Especial

3. Formecion de Promotores de Salud

4. Apertura de 800 Hogares Matemo Infanti

5. Formación de 125 Gupos de Saneamienlo

6. Rehatitacith y Forteciniento de Sentricios de Salud

7. Becas para Desmovitizados

o. Rehatitacin y Fotalecitiento de Senvins de Edracion

9. Capacilación Productiva

10. Vivienda

11. Programa de Iniraestructura Básica

12. Documenleción

13. Apoyo Inlegral a Familias de Relomo

14. Programa de Pensiones a Lisiados

\section{B. INFAAESTRUCTURA}

1. Pehabirlación de la Generación de Energia

2. Rehabiliteción de la Transmision de Energla

3. Rehabilitación de la Dislribución de Energila

4. Expansión de la Generación de Energia

5. Expansión de la Transmisión de Energla

6. Expansión de la Distribución de Energla

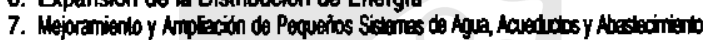

B. Programa de Reconsinucción y Ampliación del Servicio Teletónico

9. Rehabilíación de Caminos Rurales y Pequerios Puenter

10. Reconsinucción Vial y Drenaje Utbano

11. Rehabilitaciones de Hospilales

12. Programa de Restauración Integral, Universidad Nacional

C. SECTOR PRODUCTNO

1. Adquisición de Tiertas

2. Credilo Agropecuario, Pequeria y Microempresa

3. Bancos Comunales

4. Sanidad Agropecuaria

5. Asislencia Técnica Agropecuaria, Forestal y Pesquera

6. Producción de Serrilla Mejorada de Frijol

7. Programa de Desartollo de la Acuacultura

8. Rehabilitación de Pequerias Obras de Riego

9. Construcción de Pequentas Obras de Piego

10. Peconsinucción Productiva y Rehabilitación Productiva

11. Eslablecimienlo de Sislemas Agrolorestales

D. MEDIO AMBIENTE

1. Protección y manejo de Vida Silvesire

2. Establecimiento de Viveros

3. Reforeslacion

4. Conservación de Suelos

5. Control de Inundaciones

6. Educacion, Saneariento y Analisis del Impacto Ambienlal Sub-Tolal

\section{E. ASISTENCIA TECNICA} Sub-Tolal

F. FORTALECIMIENTO DEMOCRATICO

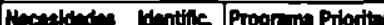

por Unled Elector

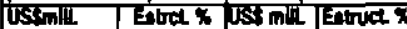

\begin{tabular}{|c|c|c|c|}
\hline $\begin{array}{r}416.90 \\
14.00 \\
3.20 \\
2.00 \\
5.40 \\
1.10 \\
20.00 \\
19.10 \\
18.00 \\
15.00 \\
95.00 \\
200.00 \\
1.50 \\
15.00 \\
7.50\end{array}$ & 29.20 & $\begin{array}{r}324.50 \\
4.70 \\
3.20 \\
0.10 \\
5.40 \\
1.10 \\
20.00 \\
19.10 \\
15.00 \\
10.00 \\
39.00 \\
200.00 \\
1.50 \\
3.00 \\
7.50\end{array}$ & 43.52 \\
\hline $\begin{array}{r}354.90 \\
37.60 \\
29.20 \\
29.60 \\
69.10 \\
27.60 \\
30.90 \\
6.10 \\
44.60 \\
58.50 \\
2.30 \\
5.00 \\
14.40\end{array}$ & 24.86 & \begin{tabular}{|r}
268.10 \\
37.90 \\
29.20 \\
29.60 \\
69.10 \\
27.60 \\
30.90 \\
6.10 \\
7.40 \\
28.50 \\
\\
2.00
\end{tabular} & 35.95 \\
\hline $\begin{array}{r}277.60 \\
50.00 \\
150.00 \\
10.00 \\
4.40 \\
12.60 \\
0.40 \\
3.20 \\
120 \\
15.30 \\
6.70 \\
23.60\end{array}$ & 19.44 & \begin{tabular}{|r}
137.50 \\
33.00 \\
58.10 \\
5.50 \\
1.00 \\
12.00 \\
0.40 \\
2.50 \\
1.20 \\
0.80 \\
12.00
\end{tabular} & 18.44 \\
\hline $\begin{array}{r}5200 \\
4.60 \\
1.10 \\
36.00 \\
6.10 \\
4.10 \\
0.10 \\
1101.40\end{array}$ & 3.64 & $\begin{array}{r}15.60 \\
2.30 \\
1.10 \\
5.00 \\
3.00 \\
4.10 \\
0.10\end{array}$ & 209 \\
\hline $\begin{array}{r}70.00 \\
1171.40\end{array}$ & 4.90 & & \\
\hline 256.50 & 17.96 & & \\
\hline & & & \\
\hline
\end{tabular}


cuales se hablan ejecutado US\$ $\mathbf{3 0 . 6}$ millones a mayo de 1993.

En el cuadro 3 se presentan las inversiones por programas para la fase I y fase II (a mayo de 1993) en el cual se puede observar que el programa de infraestructura básica es el que tienen una mayor participación dentro del total de inversiones realizadas. Este tipo de proyectos han sido ejecutados principalmente por el programa de Municipalidades en Acción (MEA), siendo los más comunes: adoquinados, reparación de caminos vecinales, dotación de mobiliario para escuelas y alcaldias, instalación de energía eléctrica y otras obras lisicas asociadas a servicios de salud, educación, agua potable, saneamiento ambiental, etc. De acuerdo a lo anterior, el PRN está concentrando sus recursos y esfuerzos sobre todo a reconstruir la infraestructura dañada durante el conflicto, generando un desbalance entre la inversión orientada a la reconstrucción de infraestructura y la orientada a generar capacidad productiva en las comunidades.

\section{CUADRO 3}

PLAN DE RECONSTRUCCION NACIONAL

MONTOS EJECUTADOS POR PROGRAMA SEGUN FASE DE IMPLEMENTACION

\begin{tabular}{|c|c|c|c|c|}
\hline \multirow[t]{2}{*}{ PROGRAMA } & \multicolumn{2}{|l|}{ FASE I } & \multicolumn{2}{|c|}{ FASE II (A MAYO 1993) } \\
\hline & MILLONES US\$ & $\%$ & MILLONES US\$ & $\%$ \\
\hline $\begin{array}{l}\text { INFRAESTRUCTURA } \\
\text { BASICA }\end{array}$ & 12.68 & 46.8 & 14.93 & 48.7 \\
\hline $\begin{array}{l}\text { REINSERCION DE } \\
\text { DESMOVILIZADOS } \\
\end{array}$ & 7.74 & 28.6 & 8.31 & 27.1 \\
\hline $\begin{array}{l}\text { DESARROLLO SOCIAL } \\
\text { Y PRODUCTIVO } \\
\end{array}$ & 4.86 & 17.9 & 5.30 & 17.3 \\
\hline ADMINISTRACION & 0.78 & 2.9 & 0.99 & 3.2 \\
\hline ALIMENTOS & 1.02 & 3.8 & 1.14 & 3.7 \\
\hline TOTAL & 27.08 & 100 & 30.67 & 100 \\
\hline
\end{tabular}

FUENTE: Elaborado en base a datos de Informe de Avance de la Secretaría de Reconstrucción Nacional a diciembre de 1992 y a mayo de 1993

Por otra parte, en ambas fases han sido los gobiernos locales los que han manejado un mayor monto de londos (Gráfico 1 y 2). 


\section{GRAFICO 1}

INVERSION PRN FASE DE CONTINGENCIA*

SEGUN TIPO DE EJECUTOR

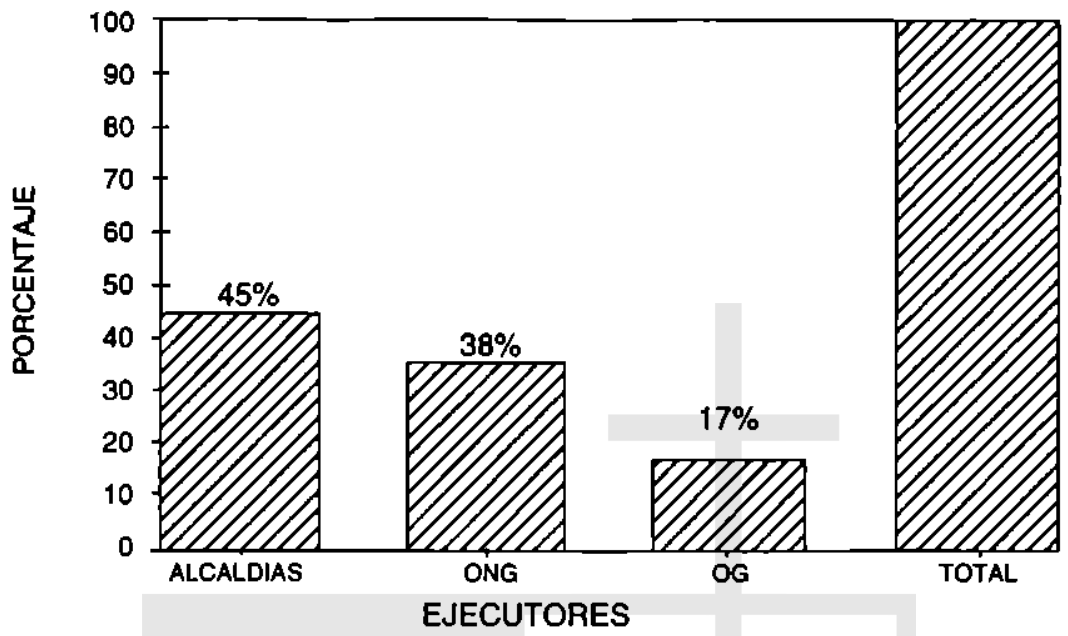

* TOTAL EJECUTADO: \$27.08 MILLONES.

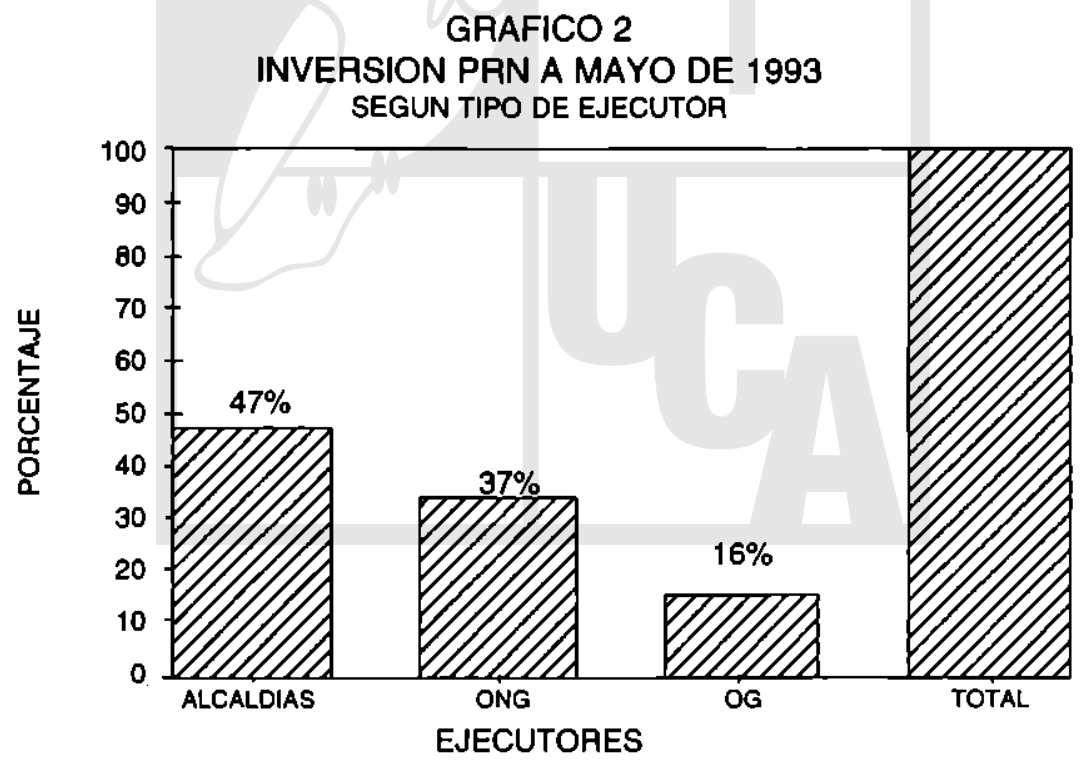

• tOTAL EJECUTADO: \$30.7 MILLONES.

616 


\section{IMPACTO MACROECONOMICO DEL PAN 1992-1997.}

El gobierno de El Salvador elaboró un estudio econométrico que hace una evaluación inicial del impacto macroeconómico que podría tener el PRN en la economía nacional en el quinquenio 1992-1997. Para la realización de dicho estudio lue necesario formular ciertos supuestos basados en el modelo de compatibilización macroeconómica utilizado por el Banco Mundial para realizar proyecciones de largo plazo. Este análisis parte de un escenario de referencia, sin PRN, donde se describe la economía del país en el período 1992-1997, sin guerra y ejecutándose únicamente el Programa Básico de Inversiones. El segundo escenario supone la ejecución completa del PRN, la consolidación de la paz y la continuidad del programa de ajuste estructural. La evaluación del impacto del PRN sobre variables macroeconómicas supone también que se contará con el financiamiento necesario para su implementación, convirtiéndose el PRN en un elemento clave para la recuperación económica y social.

Los cuadros 4 y 5 contienen los principales indicadores macroeconómicos para el periodo 1992-1997 con y sin PRN. Al comparar la información se puede observar que con la implementación de este plan habrá una mayor tasa de crecimiento y se recuperará la economía en general. La recuperación de las zonas objetivos del PRN y la ausencia del conflicto armado en el pals podrian contribuir en gran medida a la reincorporación productiva de la población y territorios mayomente afectados por el conflicto. Con este plan se fomentará la formación de capital humano y físico que con la ayuda de un mayor desarrollo de la micro y pequeña empresa vendrá a darle un mayor dinamismo a la inversión privada. Con la ayuda del sector público no financiero será posible aumentar el ahorro nacional bruto y la inversión total. A pesar que el gasto corriente es mayor en el escenario con PRN el ahorro también lo es, lo cual se debe principalmente a la mayor recaudación tributaria causada por la ampliación de la base de los principales impuestos. En cuando a la inflación, resulta ser superior con la aplicación del PRN la cual se puede atribuir a la mayor presión que sobre la demanda interna ejerce la ejecución de éste y su tendencia es a aproximarse gradualmente a los niveles internacionales. El plan tiene como objetivos reactivar las áreas cafetaleras que fueron abandonadas durante el conflicto, aumentar la superficie sembrada de productos agrícolas exportables $\theta$ incorporar la población afectada por el conflicto a la vida produotiva. Se busca incrementar sustancialemente las exportaciones, siempre que la situación económica y política del exterior nos sera favorable y exportemos aquellos productos en los que tenemos ventajas comparativas. La mayor 


\begin{tabular}{|c|c|c|c|c|c|c|c|c|}
\hline \multicolumn{9}{|c|}{$\begin{array}{c}\text { CUADRO } 4 \\
\text { PRINCIPALES INDICAOORES MACROECONOMICOS } \\
\text { ESCENARIO DE REFERENCIA: CON PLAN DE RECONSTRUCCION NACIONAL }\end{array}$} \\
\hline & 1990 & 1991 & 1892 & 1993 & 1994 & 1995 & 1096 & 1997 \\
\hline \multicolumn{9}{|l|}{ CAECAMENTO, AHORAO E RNERSION (X DE P1B) } \\
\hline PIB real (fase de crecimiento) & 3.4 & 3.5 & 4.7 & 5.5 & 6.0 & 6.0 & 6.0 & 6.0 \\
\hline $\begin{array}{l}\text { Inversion Tolal } \\
\text { Privada } \\
\text { Pública } \\
\text { Financiamienlo Tolal } \\
\text { Ahorro Nacional Bnto } \\
\text { Privado } \\
\text { Público } \\
\text { Ahorro Externo }\end{array}$ & $\begin{array}{r}11.6 \\
9.5 \\
2.3 \\
11.6 \\
5.2 \\
5.5 \\
-0.3 \\
6.6\end{array}$ & $\begin{array}{r}13.7 \\
10.9 \\
2.8 \\
13.7 \\
7.9 \\
8.4 \\
-0.5 \\
5.8\end{array}$ & $\begin{array}{r}14.2 \\
10.8 \\
3.4 \\
14.2 \\
0.9 \\
9.0 \\
-0.1 \\
5.3\end{array}$ & $\begin{array}{r}16.7 \\
11.9 \\
44.8 \\
16.7 \\
10.7 \\
10.3 \\
0.4 \\
6.0\end{array}$ & $\begin{aligned} 18.0 \\
13.0 \\
5.0 \\
18.0 \\
11.4 \\
10.8 \\
0.6 \\
6.6\end{aligned}$ & $\begin{array}{r}18.5 \\
13.8 \\
4.7 \\
18.5 \\
12.1 \\
11.0 \\
1.1 \\
6.4\end{array}$ & $\begin{array}{r}19.0 \\
14.6 \\
4.4 \\
19.0 \\
12.8 \\
11.2 \\
1.6 \\
6.2\end{array}$ & $\begin{array}{r}18.5 \\
15.7 \\
2.8 \\
18.5 \\
13.0 \\
10.9 \\
2.1 \\
5.5\end{array}$ \\
\hline 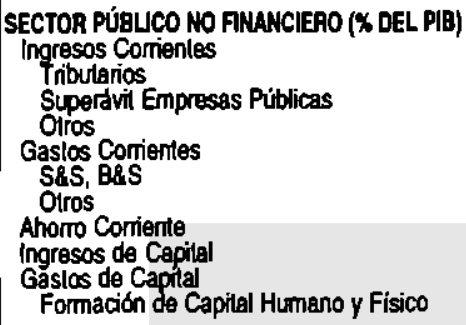 & $\begin{array}{r}11.1 \\
8.1 \\
0.7 \\
2.3 \\
11.4 \\
0.9 \\
2.5 \\
-0.3 \\
0.0 \\
2.2 \\
2.1\end{array}$ & $\begin{array}{r}11.6 \\
0.5 \\
0.7 \\
2.4 \\
12.2 \\
8.7 \\
3.5 \\
-0.5 \\
0.0 \\
3.7 \\
3.0\end{array}$ & $\begin{array}{r}11.4 \\
8.6 \\
0.6 \\
2.2 \\
11.5 \\
6.5 \\
3.0 \\
-0.1 \\
0.0 \\
4.3 \\
4.1\end{array}$ & $\begin{array}{r}12.5 \\
9.4 \\
1.1 \\
2.0 \\
12.1 \\
8.9 \\
3.2 \\
0.4 \\
0.0 \\
5.1 \\
4.8\end{array}$ & \begin{tabular}{r|}
13.1 \\
10.1 \\
1.0 \\
2.0 \\
12.5 \\
9.2 \\
3.3 \\
0.6 \\
0.0 \\
5.2 \\
5.0
\end{tabular} & \begin{tabular}{r|}
13.6 \\
10.9 \\
1.0 \\
1.7 \\
12.5 \\
9.5 \\
3.0 \\
1.1 \\
0.0 \\
5.0 \\
4.7
\end{tabular} & \begin{tabular}{r|}
14.2 \\
11.5 \\
1.0 \\
1.7 \\
12.6 \\
9.8 \\
2.8 \\
1.6 \\
0.0 \\
4.6 \\
4.4
\end{tabular} & $\begin{array}{r}14.8 \\
12.2 \\
1.0 \\
1.6 \\
12.7 \\
10.2 \\
2.5 \\
2.1 \\
0.0 \\
3.0 \\
2.8\end{array}$ \\
\hline 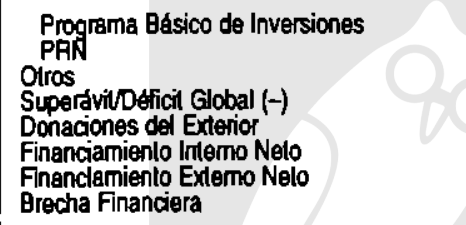 & $\begin{array}{r}2.1 \\
0.0 \\
0.1 \\
-2.5 \\
2.2 \\
-1.0 \\
1.3 \\
0.0\end{array}$ & $\begin{array}{r}3.0 \\
0.0 \\
0.7 \\
-4.2 \\
1.8 \\
0.7 \\
1.7 \\
0.0\end{array}$ & \begin{tabular}{r|}
3.4 \\
0.7 \\
0.2 \\
-4.4 \\
1.1 \\
1.0 \\
1.6 \\
0.7
\end{tabular} & $\begin{array}{r}3.0 \\
1.6 \\
0.3 \\
-4.7 \\
0.2 \\
1.4 \\
1.3 \\
1.8\end{array}$ & \begin{tabular}{r|}
3.2 \\
1.0 \\
0.2 \\
-4.6 \\
0.1 \\
1.2 \\
1.5 \\
1.8
\end{tabular} & $\begin{array}{r}2.9 \\
1.6 \\
0.3 \\
-3.9 \\
0.1 \\
0.4 \\
1.6 \\
1.8\end{array}$ & $\begin{array}{r}2.9 \\
1.5 \\
0.2 \\
-3.0 \\
0.1 \\
-0.1 \\
1.5 \\
1.5\end{array}$ & $\begin{array}{r}2.6 \\
0.2 \\
0.2 \\
-0.9 \\
0.1 \\
-0.6 \\
1.2 \\
0.2\end{array}$ \\
\hline TASA DE INFLACION (\% ANUAL) & 23.2 & 125 & 9.0 & 9.0 & 8.0 & 8.0 & 7.0 & 7.0 \\
\hline \multicolumn{9}{|l|}{ BALANZA DE PAGOS (MILL DE USS) } \\
\hline 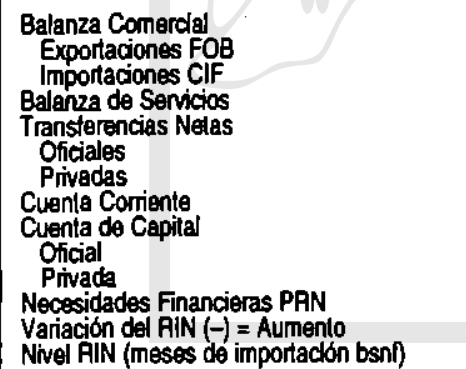 & $\begin{array}{r}-682 \\
581 \\
1263 \\
-23 \\
566 \\
223 \\
345 \\
-135 \\
290 \\
25 \\
265 \\
0 \\
-155 \\
3.6\end{array}$ & $\begin{array}{r}-018 \\
5686 \\
1406 \\
-21 \\
672 \\
179 \\
493 \\
-169 \\
183 \\
38 \\
145 \\
0 \\
-15 \\
3.3\end{array}$ & $\begin{array}{r}-879 \\
621 \\
1500 \\
-5 \\
707 \\
160 \\
527 \\
-177 \\
115 \\
35 \\
80 \\
121 \\
-59 \\
3.5\end{array}$ & $\begin{array}{r}-950 \\
732 \\
1682 \\
3 \\
650 \\
150 \\
500 \\
-297 \\
152 \\
72 \\
80 \\
210 \\
-73 \\
3.6\end{array}$ & $\begin{array}{r}-1034 \\
831 \\
1865 \\
15 \\
625 \\
150 \\
475 \\
-394 \\
207 \\
127 \\
80 \\
241 \\
-54 \\
3.6\end{array}$ & \begin{tabular}{r|r|}
-1083 \\
979 \\
2062 \\
51 \\
600 \\
150 \\
450 \\
-432 \\
276 \\
196 \\
80 \\
203 \\
-49 \\
3.5
\end{tabular} & $\mid \begin{array}{r}-1141 \\
1134 \\
2275 \\
75 \\
600 \\
150 \\
450 \\
-465 \\
366 \\
286 \\
80 \\
181 \\
-62 \\
3.6\end{array}$ & $\begin{array}{r}-1164 \\
1319 \\
2483 \\
113 \\
600 \\
150 \\
450 \\
-450 \\
403 \\
323 \\
80 \\
11 \\
37 \\
3.1\end{array}$ \\
\hline \multicolumn{9}{|l|}{ DEUDA EXTERNA (MILLL DE USS) } \\
\hline Saldo Deuda Mediano y Largo Plazo & 2030 & 2068 & 2105 & 2207 & 2401 & 2650 & 2907 & 3319 \\
\hline $\begin{array}{l}\text { Saldo Deuda Med.LP. Exp.B. y S. (\%) } \\
\text { Servicio Deuda Med.L.PJExp.B. S. } \% \text { \%) } \\
\text { Intereses Med. LPJPIB Nom US\$ (\%) }\end{array}$ & $\begin{array}{r}224.3 \\
27.2 \\
2.1\end{array}$ & $\begin{array}{r}222.4 \\
44.0 \\
2.0\end{array}$ & $\begin{array}{r}215.2 \\
25.1 \\
1.7\end{array}$ & $\begin{array}{r}195.1 \\
23.1 \\
1.7\end{array}$ & $\begin{array}{r}189.6 \\
23.3 \\
1.7\end{array}$ & $\begin{array}{r}181.1 \\
19.5 \\
1.5\end{array}$ & $\begin{array}{r}177.3 \\
18.3 \\
1.5\end{array}$ & $\begin{array}{r}170.1 \\
17.2 \\
1.6\end{array}$ \\
\hline \multicolumn{9}{|l|}{ PARTIDAS INFORMATVAS } \\
\hline $\begin{array}{l}\text { PIB Nominal (MII. US\$) } \\
\text { PIB Nominal (Mil. Colones) }\end{array}$ & $\begin{array}{r}5,402 \\
41,057\end{array}$ & $\begin{array}{r}5,950 \\
47,637 \\
\end{array}$ & $\begin{array}{r}6,689 \\
54,596 \\
\end{array}$ & $\begin{array}{r}7,393 \\
62,783 \\
\end{array}$ & $\left|\begin{array}{r}0,142 \\
71,874\end{array}\right|$ & $\begin{array}{r}9,042 \\
82,201\end{array}$ & $\begin{array}{r}9,949 \\
93,323\end{array}$ & $\begin{array}{r}10,947 \\
105,847\end{array}$ \\
\hline
\end{tabular}




\begin{tabular}{|c|c|c|c|c|c|c|c|c|}
\hline \multicolumn{9}{|c|}{$\begin{array}{c}\text { CUADRO } 5 \\
\text { PRINCIPALES INDICADORES MACROECONOMICOS } \\
\text { ESCENARIO DE REFERENCIA: SIN PLAN DE RECONSTRUCCION NACIONAL }\end{array}$} \\
\hline & 1890 & 1991 & 1092 & 1993 & 1994 & 1805 & 1900 & 1097 \\
\hline \multicolumn{9}{|l|}{ CAEC CENTO, AHOHRO E NVERSKON (X DE P(B) } \\
\hline PIB real (lase de crecimiento) & 3.4 & 3.5 & 4.0 & 4.5 & 4.5 & 4.5 & 4.5 & 4.5 \\
\hline $\begin{array}{l}\text { Irversión Tolal } \\
\text { Privada } \\
\text { Pública } \\
\text { Financlamiento Tolal } \\
\text { Ahorro Nacional Brulo } \\
\text { Privado } \\
\text { Público } \\
\text { Ahorro Externo }\end{array}$ & $\begin{array}{r}11.6 \\
9.5 \\
2.3 \\
11.8 \\
5.2 \\
5.5 \\
-0.3 \\
6.6\end{array}$ & $\begin{array}{r}13.7 \\
10.9 \\
2.8 \\
13.7 \\
7.9 \\
0.4 \\
-0.5 \\
5.8\end{array}$ & $\begin{array}{r}14.3 \\
10.9 \\
3.4 \\
14.3 \\
8.9 \\
8.9 \\
-0.0 \\
5.4\end{array}$ & $\begin{array}{r}14.6 \\
11.5 \\
3.1 \\
14.6 \\
6.7 \\
8.4 \\
0.3 \\
5.9\end{array}$ & $\begin{array}{r}15.1 \\
11.0 \\
3.3 \\
15.1 \\
9.2 \\
0.0 \\
0.4 \\
5.9\end{array}$ & $\begin{array}{r}15.6 \\
12.3 \\
3.3 \\
15.6 \\
10.1 \\
9.5 \\
0.6 \\
5.5\end{array}$ & $\begin{array}{r}16.1 \\
12.6 \\
3.3 \\
16.1 \\
11.0 \\
9.9 \\
1.1 \\
5.1\end{array}$ & $\begin{array}{r}16.4 \\
13.4 \\
3.0 \\
16.4 \\
11.8 \\
10.5 \\
1.3 \\
4.6\end{array}$ \\
\hline 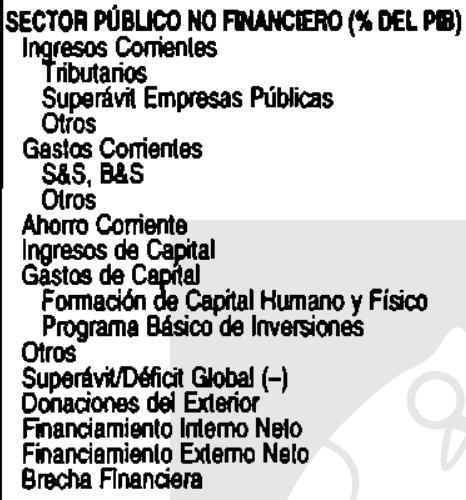 & \begin{tabular}{r|r|}
11.1 \\
8.1 \\
0.7 \\
2.3 \\
11.4 \\
8.9 \\
2.5 \\
-0.3 \\
0.0 \\
2.2 \\
2.1 \\
2.1 \\
0.1 \\
-2.5 \\
2.2 \\
-1.0 \\
1.3 \\
0.0
\end{tabular} & $\begin{array}{r}11.6 \\
8.5 \\
0.7 \\
2.4 \\
12.2 \\
8.7 \\
3.5 \\
-0.5 \\
0.0 \\
3.7 \\
3.0 \\
3.0 \\
0.7 \\
-4.2 \\
1.0 \\
0.7 \\
1.7 \\
0.0\end{array}$ & $\begin{array}{r}11.6 \\
8.7 \\
0.6 \\
2.3 \\
11.6 \\
0.5 \\
3.1 \\
0.0 \\
0.0 \\
3.7 \\
3.5 \\
3.5 \\
0.2 \\
-3.7 \\
1.1 \\
1.0 \\
1.6 \\
0.0\end{array}$ & $\begin{array}{r}12.3 \\
9.1 \\
1.1 \\
2.1 \\
12.0 \\
8.7 \\
3.3 \\
0.3 \\
0.0 \\
3.4 \\
3.1 \\
3.1 \\
0.3 \\
-3.1 \\
0.2 \\
1.2 \\
1.3 \\
0.4\end{array}$ & \begin{tabular}{r|}
12.6 \\
9.6 \\
1.0 \\
2.0 \\
12.2 \\
8.8 \\
3.4 \\
0.4 \\
0.0 \\
3.6 \\
3.3 \\
3.3 \\
0.3 \\
-3.2 \\
0.1 \\
1.1 \\
1.6 \\
1.8
\end{tabular} & $\begin{array}{r}12.7 \\
10.0 \\
1.0 \\
1.7 \\
12.1 \\
8.9 \\
3.2 \\
0.6 \\
0.0 \\
3.5 \\
3.3 \\
3.3 \\
0.2 \\
-2.9 \\
0.1 \\
0.3 \\
1.7 \\
0.8\end{array}$ & $\begin{array}{r}13.1 \\
10.5 \\
0.9 \\
1.7 \\
12.0 \\
9.1 \\
2.9 \\
1.1 \\
0.0 \\
3.5 \\
3.3 \\
3.3 \\
0.2 \\
-2.4 \\
0.1 \\
0.0 \\
1.7 \\
0.6\end{array}$ & $\begin{array}{r}13.3 \\
10.8 \\
0.9 \\
1.6 \\
12.0 \\
9.3 \\
2.7 \\
1.3 \\
0.0 \\
3.2 \\
3.0 \\
3.0 \\
0.2 \\
-1.9 \\
0.1 \\
-0.7 \\
1.4 \\
1.1\end{array}$ \\
\hline \multicolumn{9}{|l|}{ TASA DE INFLACIÓN (\% ANUAL) } \\
\hline $\begin{array}{l}\text { Interma (Defiactor del PI } \\
\text { Extema (MUVI) }\end{array}$ & $\begin{array}{r}23.2 \\
5.7\end{array}$ & $\begin{array}{r}125 \\
2.0\end{array}$ & $\begin{array}{l}8.0 \\
2.8\end{array}$ & $\begin{array}{l}7.0 \\
3.9\end{array}$ & $\begin{array}{r}7.0 \\
3.9\end{array}$ & $\begin{array}{l}6.0 \\
3.8\end{array}$ & $\begin{array}{l}6.0 \\
3 . \theta\end{array}$ & $\begin{array}{l}5.0 \\
3.8\end{array}$ \\
\hline \multicolumn{9}{|l|}{ BALANZA DE PAGOS (MILL. DE US\$) } \\
\hline $\begin{array}{l}\text { Balanza Comercial } \\
\text { Exportaciones FOB } \\
\text { Importaciones ClF } \\
\text { Balanza de Servicios } \\
\text { Transferencias Netas } \\
\text { Oficiales } \\
\text { Privadas } \\
\text { Cuenta Coriente } \\
\text { Cuenta de Capilal } \\
\text { Oficial } \\
\text { Privada } \\
\text { Variadón del RIN (-) = Aumento } \\
\text { Nivel RIN (meses de imporlación bsnt) }\end{array}$ & $\begin{array}{r}-6892 \\
581 \\
1263 \\
-23 \\
566 \\
223 \\
345 \\
-135 \\
290 \\
25 \\
265 \\
-155 \\
3.6\end{array}$ & $\begin{array}{r}-818 \\
588 \\
1406 \\
-21 \\
672 \\
179 \\
493 \\
-168 \\
163 \\
38 \\
145 \\
-15 \\
3.3\end{array}$ & $\begin{array}{r}-879 \\
621 \\
1500 \\
-5 \\
707 \\
160 \\
527 \\
-177 \\
115 \\
35 \\
80 \\
62 \\
2.7\end{array}$ & $\begin{array}{r}-915 \\
711 \\
1626 \\
0 \\
650 \\
150 \\
500 \\
=265 \\
127 \\
72 \\
55 \\
138 \\
1.6\end{array}$ & \begin{tabular}{r|}
-943 \\
012 \\
1755 \\
16 \\
625 \\
150 \\
475 \\
-297 \\
182 \\
127 \\
55 \\
115 \\
0.8 \\
\end{tabular} & \begin{tabular}{r|}
960 \\
845 \\
1907 \\
60 \\
600 \\
150 \\
450 \\
-302 \\
253 \\
198 \\
55 \\
49 \\
0.5
\end{tabular} & $\begin{array}{r}-996 \\
1078 \\
2074 \\
96 \\
600 \\
150 \\
450 \\
-299 \\
341 \\
286 \\
55 \\
-42 \\
0.6\end{array}$ & $\begin{array}{r}-1025 \\
1231 \\
2256 \\
143 \\
600 \\
150 \\
450 \\
-231 \\
376 \\
322 \\
55 \\
-97 \\
1.0\end{array}$ \\
\hline \multicolumn{9}{|l|}{ DEUDA EXTERNA (MILLL DE US\$) } \\
\hline 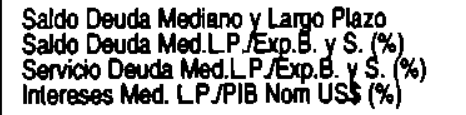 & $\begin{array}{r}2030 \\
224.3 \\
27.2 \\
2.1\end{array}$ & $\begin{array}{r}2068 \\
222.4 \\
44.0 \\
2.0\end{array}$ & $\begin{array}{r}2103 \\
215.0 \\
25.1 \\
1.7\end{array}$ & \begin{tabular}{r|r|}
2175 \\
197.0 \\
23.6 \\
1.8
\end{tabular} & $\begin{array}{r}2302 \\
184.9 \\
23.4 \\
1.7\end{array}$ & $\begin{array}{r}2500 \\
175.3 \\
19.2 \\
1.5\end{array}$ & $\begin{array}{r}2786 \\
172.0 \\
17.7 \\
1.5\end{array}$ & $\begin{array}{r}3109 \\
167.8 \\
16.2 \\
1.5\end{array}$ \\
\hline \multicolumn{9}{|l|}{ PARTIDAS INFORMATIVAS } \\
\hline $\begin{array}{l}\text { PIB Nominal (Mill. USS) } \\
\text { PIB Nominal (Mill. Colones) }\end{array}$ & $\begin{array}{r}5,402 \\
41,057\end{array}$ & $\begin{array}{r}5,950 \\
47,937\end{array}$ & $\begin{array}{r}6,577 \\
54,731\end{array}$ & $\begin{array}{r}7,075 \\
60,080\end{array}$ & 67,610 & $\begin{array}{r}8,178 \\
74,413\end{array}$ & $\left|\begin{array}{r}6,797 \\
62,427\end{array}\right|$ & $\begin{array}{r}9,354 \\
90,443\end{array}$ \\
\hline
\end{tabular}


confianza propiciada por las perspectivas de paz vendrá a incrementar el flujo de divisas provenientes del exterior, ya sea inversiones extranjeras o capilales privados repatriados.

En cuanto a la deuda externa, todo indica que se incrementará ya que para poder realizar todos los proyectos propuestos es necesario un significativo monto para su financiamiento. Pero si todos los préstamos se invirtieran eficientemente en proyectos que contribuyan al desarrollo se podrla tener la capacidad de pago necesaria para mantener el nivel de la deuda en los márgenes aceptables por los estándares internacionales.

A pesar de las consideraciones anteriores podemos asegurar que el Programa Básico de Inversiones en conjunto con el PRN vendrán a incrementar la inversión total pero no al ritmo que se plantea en el estudio, ya que aunque existe una mayor confianza propiciada por las perspectivas de paz, existen otras variables que también condicionan la inversión (tasa de interés, inflación, calidad de la mano de obra, etc.). En cuanto a las finanzas públicas se observa que todas las reformas tributarias tendientes a modernizar y hacer más eficiente la administración no han logrado contribuir en la medida necesaria para proporcionar un ámbito favorable para el desarrollo del PRN. Según proyecciones realizadas por el BCR se considera que el nivel de inflación no va a ser tan bajo como lo indican los datos de MIPLAN. Por otra parte, la vulnerabilidad de nuestra economía con respecto al sector externo nos proporciona un indicador de lo importante que es la estabilidad del mercado internacional para nuestra balanza de pagos y expresa la necesidad de una agresiva politica de diversificación de exportaciones. Al mismo tiempo, las donaciones y préstamos del exterior para financiar el PRN dependen mucho de decisiones politicas de los donantes, lo cual condiciona la recuperación económica y social del país al no contar con el financiamiento suficiente para la culminación del plan.

\section{EVALUACION DEL PLAN DE RECONSTRUCCION NACIONAL}

A continuación se presenta la parte analítica del trabajo en la cual se evalua la relación que existe entre el PRN y el Plan de Desarrollo, se definen los elementos del PRN que estan acordes con los planteamientos de la CEPAL y qué perspectivas hay de incorporar estos elementos en los próximos planes de desarrollo, luego se presentan los logros económicos y sociales de la fase I del plan y las opiniones respecto al mismo de distintos agentes que han emilido criticas al respecto. 


\section{A. INTEGRACION DEL PRN AL PLAN DE DESARROLLO ECONOMI- CO Y SOCIAL 1989-1994}

Lo que se pretende en este apartado es determinar si el PRN es un plan complementario al Plan de Desarrollo, el cual representa al gran modelo económico y social de la nación. Se establecerá el grado de inlegración que existe entre ambos, es decir si comparten los mismos principios filisóficos o postulados económicos-sociales, pues cada uno de ellos tiene sus propios objetivos, políticas generales y particulares y estrategias. Será importante establecer si se contradicen o no; en qué sentido se afectan y si ambos apuntan en una misma dirección, de tal manera que permita determinar si es factible y además apropiado, ejecutar una serie de proyectos como los contemplados en el PRN y en el modelo actual, o si va a ser necesario reformular alguno de ellos.

A.1) Principios filosóficos, postulados económicos y sociales. En principio, cada uno de los planes tiene una forma diferente de apreciar la realidad pues el contexto en el que se desarrollan tambien es distinto. El Plan de Desarrollo fue desarrollado únicamente por el gobiemo de El Salvador, tiene un respaldo electoral y contiene el conjunto de políticas a aplicar en todo el periodo de vigencia, las cuales ejercen un impacto global en la economla nacional. En cambio el PRN, es un plan de postguerra que interviene específicamente en los problemas causados por el conflicto y surge de un acuerdo político entre el gobierno y el FMLN.

A continuación analizaremos los principios filosóficos en que se sustenta el Plan de desarrollo de cara a la realidad de nuestro país. 5

1) El hombre es el fin de toda sociedad: este principio es muy individualista, pues el hombre debe estar al servicio de la sociedad y ésta no debe concebirse como una sumatoria de individuos.

En este sentido el PRN no comparte esle principio pues se preocupa por el bienestar de la comunidad orientando los proyectos para el beneficio de toda la población.

2) La libertad es la base del progreso humano. En nuestro modelo actual no se cumple este principio, pues no todos somos libres. Esta libertad se define como ausencia de coacción y no como responsabilidad social. Se dice también que el limite a la libertad de una persona radica en el punto donde comienza la de otra. El problema estriba en qué y cómo se van a determinar estos límites para que no sean desiguales.

5. Ver Ibisale, Francisco J., "EI programa de ajuste estructural: una herencia diliciln. 
El PRN trata más bien de crear una responsabilidad comunitaria, una conciencia de solidaridad y colaboración, la sociedad aparece como una interacción de personas y no como una sumatoria de individuos. EI PRN es propiamente comunitario y la libertad neoliberal es más individualista y competitiva.

3) La justicia garantiza a cada quien lo que le corresponde.

No tenemos igualdad de condiciones ni oportunidades, por lo tanto la justicia no nos puede garantizar lo que a cada quien le corresponde.

4) La igualdad ante la ley es la garante de la paz social.

EI PRN busca favorecer a los más pobres, creando condiciones de igualdad entre todos los miembros de la sociedad, sin discriminaciones ni privilegios. Por lo tanto, busca cumplir con este principio como requisito para lograr la paz.

5) El estado desempeña un papel subsidiario.

Debido a que el PRN no se aplica en una sociedad libre y equitativa. El estado no puede asumir un papel subsidiario, sino que debe garantizar, en el caso de que existan mercados, que funcionen libremente sin abusos ni manipulaciones. De lo contrario el estado debe desempeñar un papel de proveedor.

Por otro lado, el PRN, para realizar la estrategia económica se basó en postulados diferentes a los planteados en el plan de desarrollo. En las zonas objetivo del PRN la pobreza suplanta a la propiedad privada, la competencia empresarial es inexistente por ser inexistentes los servicios y las unidades de producción privadas y públicas; no hay espacio para un mercado donde puedan jugar las fuerzas de la oferta y la demanda; y el estado mas que subsidiario, economómicamente estuvo ausente, dejando lodo el campo libre a la instalación de la guerra.

\section{A.2) Objetivos, política económicas y social.}

Ambos planes comparten los mismos objetivos generales, pues buscan el desarrollo económico y social, pero cada uno tienen sus propios objetivos especifficos, políticas estrategias y principios.

Debido a que el plan de desarrollo fue el primero en ponerse en marcha se le da el derecho de primogenitura, lo que significa que es el PRN el que de alguna manera debe adaptarse a los programas de estabilización y ajuste estructural del plan de desarrollo. Por lo tanto, para que ambos planes logren conjuntamente los objetivos propuestos es necesario un desarrollo integral y armónico de sus partes, es decir que lleven una misma dirección y orientación económica y social, de tal 
manera que no profundicen los desequilibrios existentes en nuestra economia.

Aún con las divergencias en sus postulados y principios económicos señalados anteriormente se puede apreciar que comparten en gran medida varios objetivos, lo cual es lógico si tomamos en cuenta que ambos son responsabilidad del Gobiemo de El Salvador.

Los dos plantean acelerar el proceso de desarrollo económico y social mediante la creación de las condiciones para alcanzar un crecimiento robusto y sostenidc, elevando la calidad y mejorando las condiciones de vida de toda la población, especialmente la que vive en extrema pobreza. La diferencia es que el plan de desarrollo sólo ha acelerado el proceso de crecimiento económico, dejando casi en el olvido el desarrollo social. Esta situación se explica porque uno de sus principios es crecer y luego distribuir, además sostiene que el estado debe desempeñar un papel subsidiario lo cual no le permite incrementar los gastos en las áreas sociales, en razón de mejorar los desequilibrios fiscales.

En ambos planes se habla de una participación democratica y se busca la descentralización del estado, pero es hasta la implementación del PRN que estos objetivos se han puesto en marcha.

Por otra parte, no concuerdan en la orientación de las estrategias de crecimiento. El plan de desarrollo busca este objetivo mediante pollticas de crecimiento hacia afuera, corrigiendo los desequilibrios externos; en cambio el PRN procura satisfacer las necesidades internas.

Además, el plan de desarrollo convierte a la capital en el epicientro económico sobre el cual pivotea el crecimiento, por el contrario el PRN busca crear polos de desarrollo en cada uno de los municipios.

A partir de estas observaciones se puede decir que estos planes no se integran ni son complementarios pues el PRN viene a calmar o suplir lo que el gobierno ha olvidado, es decir al hombre. EI PRN rescata el desarrollo social actuando sobre las comunidades que fueron abandonadas por el plan de desarrollo (por falta de interés político, la guerra, elc.).

\section{B) EL PRN EN EL MARCO TEORICO DE EQUIDAD Y TRANSFOR- MACION PRODUCTIVA.}

El marco de equidad y transformación productiva se refiere a lodo un gran modelo económico, por esta razón es necesario evaluar inicialmente si el plan de desarrollo está acorde con esos lineamientos.

Para la consecución del desarrollo económico y social, el actual plan 
de desarrollo se basa en la teoría del rebalse, es decir no pretende alcanzar simultáneamente el crecimiento y la equidad pues considera que no existe incompatibilidad entre estos objetivos, pero si un problema de tiempo, ya que es necesario buscar primeramente un crecimiento sostenido y luego esperar que los frutos de éste beneficien a las grandes mayorias. En este sentido, no comparte los criterios o lineamientos propuestos por la CEPAL. Desde esta perspectiva es necesario reformular el modelo a aplicar en el siguiente periodo y tratar de adoptar los lineamientos de la CEPAL, como en alguna medida lo esta haciendo el PRN.

Para el PRN la consecución del desarrollo económico y social simultáneo es uno de sus principlaes objetivos (aunque implicito), entendiendo desarrollo como crecimiento económico acompañado de igualdad de oportunidades y condiciones para acceder a una distribución más equitativa del mismo, incluyendo equidad jurídica, politica y social.

El fin último del PRN no es sólo aliviar momentáneamente el deterioro de la infraestructura y los niveles de vida de la población sino que pretende mediante una transformación productiva, contribuir a acelerar el proceso de desarrollo. Dicho plan está sentando las bases para un nuevo proceso de desarrollo, en donde loda la población pueda participar y gozar de sus frutos.

A pesar de eslo el PRN adolece de una desventaja, en el sentido de que su volumen monetario es reducido dentro del PIB, por lo tanto su impacto no será de grandes dimensiones. Sin embargo, el PRN unido con otros hechos nacionales, puede crear y parecerla que está creando una nueva conciencia social para remodelar el plan de desarrollo nacional. Eslo se ve reflejado en el hecho de que los planes de gobierno propuestos por los distintos partidos políticos para el próximo perlodo presidencial tienen una preocupación por que se realicen esfuerzos en áreas de educación, salud, protección de la familia y medio ambiente.

C) LOGROS ECONOMICOS Y SOCIALES. A continuación se presentan algunos logros que se derivan de las entrevistas realizadas a las personas beneficiarias, otros que percibimos al visitar distintos lugares e instiluciones involucradas y los que pueden surgir de los resultados de la fase de contingencia.

- Consideramos que el hecho de haber ejecutado el $49 \%$ de lo planeado es un gran logro pues se han enfrentado problemas tanto financieros como los que implicaba la novedad e inexperiencia en la realización de un plan de la naturaleza del PRN. 
- Un gran avance en materia de política económica es que en el PRN existe una mayor preocupación por la población que por variables económicas, situándose en las zonas exconflictivas, abandonadas y más pobres para satisfacer sus necesidades sociales.

- Adicionalmente se están satisfaciendo las necesidades que la población considera más urgentes expresadas a través de la participación comunitaria en los Cabildos Abiertos. La Secretarla de Reconstrucción ha actuado en lo que la comunidadd solicitó. En este sentido se esta dando una descentralización de las acciones del gobierno, pero únicamente en lo relacionado con la presentación, por parte de la misma población, de los problemas y necesidades que los afectan.

- Otro aspecto positivo propiciado por la ejecución del PRN es que ha generado empleo, aunque temporal, en las instituciones públicas y privadas que han sido contratadas para realizar los proyectos, también se ha requerido eventualmente mano de obra de pobladores del lugar donde se realizan estos proyectos, generando oportunidades de mejorar sus ingresos.

- El mismo gobierno ya no concibe a la capital como epicentro del desarrollo, está tratando de formar pequeños polos en las municipalidades a Iravés de la generación de condiciones laborales y básicas favorables que hagan atrayente el área rural y evitar de esta manera la continua migración del campo hacia la ciudad.

- En cuanto a logros eminentemente económicos podemos destacar que el PIB real para 1992 creció según lo previsto (4.65\%), siendo el mayor incremento registrado desde 1978. Sin embargo esta recuperación en el crecimiento económico no podemos atribuirlo exclusivamente a la ejecución de la lase de contingencia sólo representó, aproximadamente, $0.4 \%$ del PIB. A pesar de esto el BID atribuye la recuperación en la inversión a la implementación de los programas de reconstrucción: "... el término de la guerra que duró 12 años y el comienzo de un importante programa de reparación de los daños causados por el conflicto, denominado Plan de Reconstrucción Nacional, propiciaron un considerable aumento de la inversión ... la inversión bruta real aumentó en El Salvador un 17 por ciento, impulsada por un incremento del 43 por ciento en las inversiones públicas." 6

6. La Prensa Gráfica, 20 octubre 1993. 


\section{D) APRECIACIONES SOBRE LA EJECUCION DEL PRN.}

El hecho de que el PRN esté hecho entre muchos participantes implica que cada uno lo visualice de forma distinta. Por lo tanto es normal que ante un hecho novedoso donde participan diversas entidades se hagan críticas positvas y negalivas respecto a un mismo punto. Esto se puede comprobar en las apreciaciones que aqul se presentan, las cuales se obluvieron por medio de entrevistas con las personas involucradas 0 a través de la lectura de documentos en la materia.

A continuación se exponen las apreciaciones del gobierno y del FMLN como principales actores en esle plan, luego se presentan las observaciones hechas por CENITEC. Estas se han seleccionado por ser las más relevantes y resumen en general las opiniones del resto de participantes. En nuestra tesis se incluyen además apreciaciones de municipalidades (Quezaltepeque, Guazapa, Berlín, Aguilares, Chalatenango), organismos gubernamentales (Banco de Tierras, Dirección General de Reconstrucción, Secretaría de Reconstrucción Nacional y FIS), organismos no gubernamentales ( $F-16$ y Catholic Relief Service) y otras instituciones (FUSADES y la Oficina General de Contabilidad de los Estados Unidos) que aparecen ampliamente desarrolladas en dicho documento.

D.1) Gobierno de El Salvador.

Según el gobiemo los principales logros y problemas del Plan de Reconstrucción se encuentran en el Recuadro 1.

D.2) Frente Farabundo Marti para la Liberación Nacional.

Por su parte el FMLN plantea que el PRN es un "rracaso", señalando las debilidades que aparecen resumidas en el Recuadro 2.

D.3) Instituto de investigación: CENITEC.

Las apreciaciones que CENITEC hace al PRN pueden verse en el Recuadro 3.

\section{V) APRECIACIONES Y CONCLUSIONES DEL GRUPO.}

Puede parecer contradictorio hacer referencia a conclusiones sobre un tema inconcluso o en vias de realización como el PRN. Pero no es contradictorio concluir si este plan, al igual que los Acuerdos de Paz, marcan el final de una etapa histórica, la guerra, y pronostican una nueva era de esperanzas, tensiones e interrogantes.

El objetivo de este trabajo era determinar el impacto que podría tener 


\begin{tabular}{|c|c|}
\hline ASPECTOS POSITIVOS & ASPECTOS NEGATIVOS \\
\hline 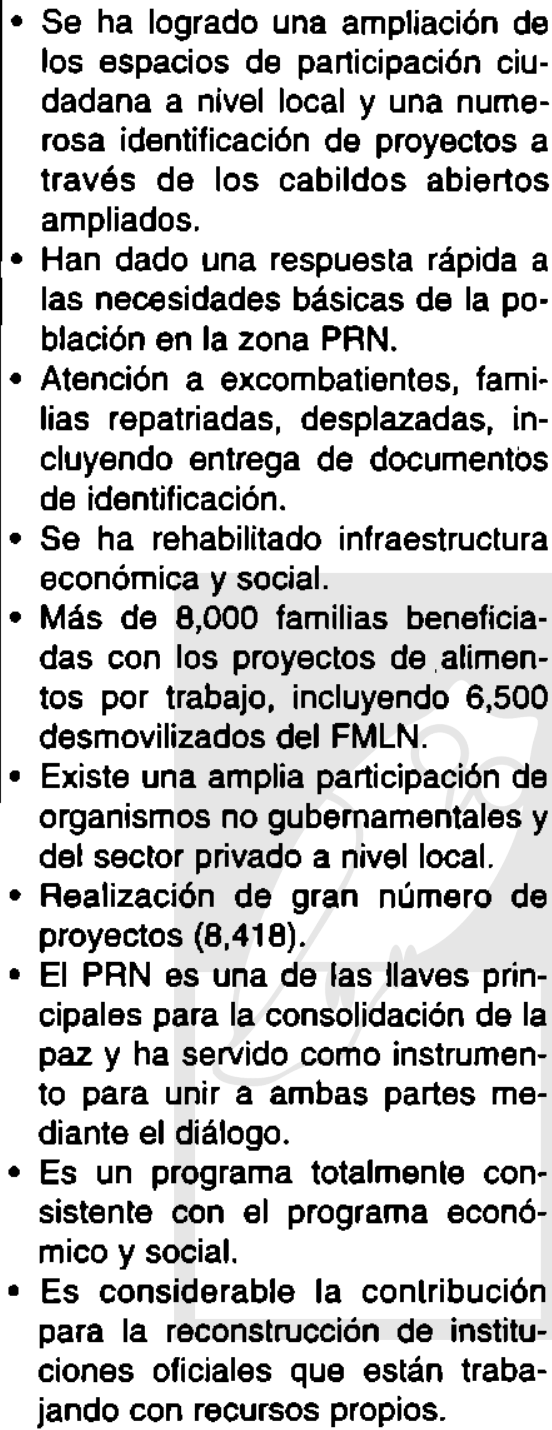 & $\begin{array}{l}\text { - Existe fricción entre algunos go- } \\
\text { biernos locales, asociaciones co- } \\
\text { munitarias y ONG, especialmente } \\
\text { donde los alcaldes estaban en el } \\
\text { exilio. } \\
\text { - La capacidad de ejecución de las } \\
\text { instituciones oficiales es limitada. } \\
\text { - Algunas ONG tienen capacidad } \\
\text { técnica, administrativa y/o financie- } \\
\text { ra limitada. } \\
\text { - Falta de precisión en el número de } \\
\text { beneficiarios especialmente de } \\
\text { personal desmovilizado. } \\
\text { - Lentitud en la concretización de } \\
\text { ofrecimientos de recursos exter- } \\
\text { nos. } \\
\text { - Recursos liscales limitados. } \\
\text { Dificultad en la reasignación de los } \\
\text { recursos hacia áreas prioritarias } \\
\text { de los Acuerdos de Paz debido a } \\
\text { comproinisos establecidos en los } \\
\text { convenios con los donantes. } \\
\text { - Ni el gobierno ni el FMLN tenian } \\
\text { experiencia sobre reinserción de } \\
\text { excombatientes, implicando solu- } \\
\text { cionar los problemas en la mar- } \\
\text { cha. }\end{array}$ \\
\hline
\end{tabular}


- El gobierno ha cerrado el proceso de concertación y evita la participación de las comunidades y organismos populares en la distribución de fondos, favoreciendo a los organismos afines al gobierno.

- El PRN se centra en reconstruir infraestructura en función de desarrollar la economia de mercado.

- El PRN ha sido instrumentalizado con fines pertidistas.

- Los proyectos realizados no reflejan las necesidades de las personas pues no se toma en cuenta la experiencia popular ni existe confianza en los cabildos abiertos ampliados.

- No es cierto que se de una amplia participación, pues la magnitud en que cada organismo participa es distinta, relegando la intervención de las ONG afines al FMLN.

- EI FIS sólo realiza proyectos de alivio a la pobreza y su prolongación cambia el rumbo de las prioridades del PRN.

- Existen numerosos obstáculos en la escrituración y entrega de tierras.

la ejecución de un plan de reconstrucción nacional sobre la economia nacional, con la limitante de tiempo que nos hace referimos a su impacto en la forma de apreciar la realidad. A continuación presentamos algunas coclusiones respecto al terna:

- Consideramos que el PRN está cumpliendo con los principios propuestos por la CEPAL sobre la consecución simultánea de crecimiento con equidad, medianle una trasnformación productiva. Es decir, que el PRN experimenta una teoria del rebalse "al revésn, enfatizando el desarrollo social como generador de crecimiento económico. En cambio en el plan de desarrollo existe un problema de tiempo, es decir que primero crece la capital y posteriormente se extiende hacia los demás territorios.

- A pesar de que hay numeroso agentes unidos en consenso para llevar adelante el proceso de reconstrucción, el grado de participación no es homogéneo, como lo asegura el FMLN. Pero esto se debe a que no todas las instituciones estan proparadas para trabajar con organismos internacionales que exigen dinamismo y tienen controles financieros y administrativos rigurosos. En el caso de las municipalidades, se enfrentan problemas de incapacidad administrativa y ejecutiva, pues la mayoria de alcaldes lienen un bajo nivel de escolaridad que no permite descentralizar el manejo de fondos mienIras no sean fortalecidos. Por otra parte, no se ha avanzado en cuanto a los niveles de participación de las comunidades, sólo se ha dado 
RECUADRO 3.

\begin{tabular}{|c|c|}
\hline ASPECTOS POSITIVOS & ASPECTOS NEGATIVOS \\
\hline $\begin{array}{l}\text { - Existe concertación entre el gobier- } \\
\text { no y el FMLN, que se ve refilejada } \\
\text { en el equilibrio que presenta el } \\
\text { PRN entre reconstrucción de infra- } \\
\text { estructura (prioridad para el gobier- } \\
\text { no) y desarrollo productivo (priori- } \\
\text { dad del FMLN). } \\
\text { - EL PRN demuestra la posibilidad } \\
\text { de solucionar los conflictos milita- } \\
\text { res a través de la via política. } \\
\text { - Es un elemento clave para satisla- } \\
\text { cer necesidades inmediatas en las } \\
\text { zonas exconflictivas, sobre lodo en } \\
\text { el corto plazo. }\end{array}$ & $\begin{array}{l}\text { - Los alcances del PRN son limita- } \\
\text { dos pues no garantizan una amplia } \\
\text { participación de todos los sectores } \\
\text { en el proceso de desarrollo econó- } \\
\text { mico, ni contiene elementos para } \\
\text { la elaboración de una estrategia de } \\
\text { desarrollo de largo plazo. } \\
\text { - Existe un problema real de partici- } \\
\text { pación pues el gobierno es el lider } \\
\text { en el diseño, seguimiento, evalua- } \\
\text { ción y administración de lodo el } \\
\text { plan. No se promueve a nivel real } \\
\text { la participación de las fuerzas so- } \\
\text { ciales involucradas. } \\
\text { - Alta vulnerabilidad del plan debido } \\
\text { a su dependencia de recursos ex- } \\
\text { ternos. } \\
\text { - Baja capacidad de ejecución del } \\
\text { gobierno. } \\
\text { - No existe vinculación entre PRN y } \\
\text { plan de desarrollo. Uno busca } \\
\text { implementar un programa de ajus- } \\
\text { te restrictivo y el otro expandir la } \\
\text { demanda. } \\
\text { - Carece de una visión integral que } \\
\text { logre articular los distintos proyec- } \\
\text { tos dentro de una estrategia global } \\
\text { de desarrollo. } \\
\text { - Los mecanismos de participación } \\
\text { no cuentan con la legitimidad de } \\
\text { los habitantes de las zonas ex- } \\
\text { conflictivas, especialmente aque- } \\
\text { llas con alcaldes en el exilio. }\end{array}$ \\
\hline
\end{tabular}


paso a la presentación de proyectos a través de cabildos abiertos ampliados, pero no a su elección, implementación y evaluación.

- El PRN ha desembolsado cerca del $50 \%$ de los tondos asignados para el año 1992, pero se ha centrado en la ejecución de pequeños proyectos de infraestructura asistiendo las necesidades más urgentes de la población. Por lo tanto, cabe esperar que la etapa de mediano plazo siente bases firmes y logre resultados de mayor alcance en materia de desarrollo económico e integración nacional. Por otra parte, a pesar que el PRN está realizando proyectos aislados, consideramos que en un futuro podrán contribuir a integrar al pals a través del surgimiento de pequeños polos económicos fuera de la capital que permitan detener la concentración de población en las ciudades.

- El gran problema de la Secretarla de Reconstrucción es que no tienen mecanismos específicos de selección y focalización de beneficiarios, no cuenta con información completa que permita asignar eficientemente los recursos, ni ha realizado evaluaciones de los resultados oblenidos hasta el momento.

- Es un reto para la nación generar fondos internamente que permitan darle mantenimiento a las obras que está realizando el PRN y a la vez permitan continuar con proyectos de reconstrucción que no tengan el peligro de ser suspendidos temporal o permanentemente, por la falta de recursos externos.

- La ejecución de cada uno de los proyectos tenía un propósito especilico, satisfacer las necesidades básicas de la población, es decir, que este plan ha atendido los problemas sociales sin enfatizar solo las variables económicas, expresandose a favor de la simultaneidad de resolver los problemas sociales y económicos, es decir considerando ambas partes de la realidad.

Por esta razón el PRN es un proyecto novedoso que muestra la realidad y las verdaderas necesidades del pueblo salvadoreño. Sin embargo estas afirmaciones no restan méritos a las variables macroeconómicas que son las que determinan el crecimiento económico que es condición necesaria para el desarrollo.

- A pesar que el gobierno de El Salvador considera compatible el Plan de Reconstrucción Nacional y el Plan de Desarrollo Económico y Social 1989-1994. De acuerdo a lo expuesto en este trabajo el PRN es mas bien corrector o suplanta to que el Plan de Desarrollo no pudo hacer. El actual plan de desarrollo se preocupó más por resolver los desequilibrios de indole económica dejando de lado las parte que correspondía a los problemas sociales, una razón puede ser que 
el presupuesto de la nación no es suficiente para atender estas necesidades, recurriendo a donaciones para satisfacer las necesidades básicas sociales.

En nuestra opinión es inhumano tener que satisfacer estas necesidades con linanciamiento externo y no tener la capacidad, ya sea administrativa o cultural, de dedicar mayor parte del presupuesto a la parte social.

En conclusión, el PRN pretende corregir o realizar lo que el plan de desarrollo no pudo poner en práctica. En este sentido consideramos que el PRN es un proyecto nacional que ha sentado las bases para que exista una mayor preocupación por elevar el bienestar y calidad de vida de la población en general, especialmente la que vive en situación de pobreza.

Esto se evidencia en las actuales plataformas de desarrollo están considerando el crecimiento con equidad, la solidaridad y el consenso, que no toma en cuenta las actuales políticas de estabilización y ajuste estructural. En este sentido, se plantea un reto para las nuevas politicas económicas y sociales incorporar elementos claves que contienen el PRN: participación concertación y donde el centro de la actividad económica sea el hombre.

- En última instancia la consecución de la paz y la linalización del proceso de reconciliación no se darán sino hasta que todos los acuerdos de paz se cumplan en su totalidad. Por lo tanto, es una limitante para la consecución de la paz el hecho que se eslé avanzando en materia social y que, por otra parte, no exista un consenso en cuestiones políticas y económicas, como es el caso del Foro para la Concertación Económica y Social, el cual hasta la fecha no ha mostrado ningún avance debido a la falta de concertación entre el gobierno, la empresa privada y los trabajadores.

En este sentido y a pesar que el PRN está sujeto a tensiones políticas, ha avanzado en sus objetivos y ha logrado desarrollar diversos proyectos. Por lo tanto, por lo novedoso del plan, todo lo que logre realizarse tiene un gran valor, pues to hace en medio de grandes tensiones y desafios.

- Para la consecución de los objetivos del PRN es necesario un tiempo prudencial, es decir esto implica todo un proceso lento, donde poco a poco se van eliminando los obstáculos para que al final de éste, se pueda determinar el cumplimiento de sus objetivos.

- Como en cualquier proyecto sociopolítico se tuvo una serie de críti- 
cas u opiniones por parte de los distintos sectores del pals, propiciadas especialmente por las distintas posiciones ideológicas existentes en el medio. En cierta medida se considera que algunas de estas apreciaciones son exageradas y tratan de desacreditar políticamenta a las insituciones involucradas en la implementación del PRN.

\section{BIBLIOGRAFIA}

- Acuerdo de Paz, en ECA, enero-lebrero 1992, No. 519-520, pág. 103-151.

- banco Central de reserva de el salvador, Revisla Trimestral, enero-marzo 1993.

- CENTRO DE INVESTIGACIONES TECNOLOGICAS Y CIENTIFICAS La reconstrucción nacional en el marco de la posiguerra, mimeo.

- CENTRO DE INVESTIGACIONES TECNOLOGICAS Y CIENTIFICAS Algunas consideraciones en torno al Plan de Reconstrucción Nacional, mimeo.

- CENTRO UNIVERSITARIO DE DOCUMENTACION E INFORMACION, UCA, "Nuevo préstamo para el Plan de Reconstrucción Nacional" en PROCESO, marzo 1993, año 13, No. 557, pág. 9-10.

- COMISION ECONOMICA PARA AMERICA LATINA Y EL CARIBE

Equidad y Translormación Productiva, Un Enfoque Integrado, Chile, CEPAL, 1992.

- FRENTE Farabundo marti para la liberacion nacional

Propuesta económica del FMLN par el desarrollo y la construcción de la nueva sociedad salvadoreña, FMLN, febrero 1992.

- FRENTE FARABUNDO MARTI PARA LA LIBERACION NACIONAL

Plan Nacional de Reconstrucción propuesta a la nación FMLN, borrador, enero 1992.

- FRENTE faRABUNdo MARTI PARA La LIBERACION NACIONAL

Entoques principales del PRN del FMLN, FMLN, enero 1992.

- FRENTE faRABUNDO MARTI PARA La LIBERACION NACIONAL

Elementos básicos sobre el Plan Nacional de Reconstrucción, FMLN, noviembre 1991.

- FRENTE FARABUNDO MARTI PARA LA LIBERACION NACIONAL

Balance del PRN elaborado por el FMLN, FMLN, diciembre 1992.

- FRENTE farabundo marti para la liberacion Nacional 
Sobre el monitoreo al PRN, FMLN, marzo 1993.

- FONDO DE INVERSION SOCIAL DE EL SALVADOR

El Salvador escenario 1992, resultados del FISS, FIS, enero 1993.

- FUNDACION 16 DE ENERO

F-16 enero 1992-enero 1993, F-16, 1993.

- Ibisale, Francisco J.

El Plan de Reconstrucción Nacional son tres: Cuál es el principal?, mimeo.

- Ibisate, Francisco J.

La política de reconstrucción nacional, mimeo.

- Ibisate, Francisco J.

"El programa de ajuste estructural: una herencia dilicil" en Realidad Económico-Social, mayo-junio 1990, año 3, No. 15.

- INSTITUTO DE INVESTIGACIONES ECONOMICAS Y SOCIALES UCA

" Plan de investigación del Instituto de Investigaciones Económicas y Sociales", en Realidad Económico-Social, mayo-junio 1991, año IV, No. 21, pág. 401431.

- Jacob, Richard

* Política social en la economia social de mercado. Qué significa social en el concepto de economla social de mercado? en Contribuciones 3/92.

- MINISTERIO DE PLANIFICACION Y COORDINACION DEL DESARROLLO ECONOMICO Y SOCIAL.

Plan de Reconstrucción Nacional (PRN), versión preliminar revisada, MIPLAN, noviembre 1991, volumen 1.

- MINISTERIO DE PLANIFICACION Y COORDINACION DEL DESARROLLO ECONOMICO Y.SOCIAL.

Plan de Reconslrucción Nacional (PRN), MIPLAN, marzo 1992, volumen 1.

- MINISTERIO DE PLANIFICACION Y COORDINACION DEL DESARROLLO ECONOMICO Y SOCIAL.

"Resumen Ejecutivo del Plan de Reconstrucción Nacional de El Salvador", en Evolución Económica, MIPLAN 1992.

- MINISTERIO DE PLANIFICACION Y COORDINACION DEL DESARROLLO ECONOMICO Y SOCIAL.

“Evaluación del Impacto Macroeconómico del PRN”, en Evolución Económica, MIPLAN 1992.

- MINISTERIO DE PLANIFICACION Y COORDINACION DEL DESARROLLO ECONOMICO Y SOCIAL. 
Plan de Desarrollo Económico y Social 1989-1994, MIPLAN 1989.

- MINISTERIO DE PLANIFICACION Y COORDINACION DEL DESARROLLO ECONOMICO Y SOCIAL.

Prioridades de Inversión Pública y Necesidades de Asistencia Técnica. Vol. 1. Texto principal, MIPLAN, abril 1991.

- MINISTRY OF PLANNING AND COORDINATION OF ECONOMIC AND SOCIAL DEVELOPMENT.

Democralic Strengthening Program, MIPLAN, March 1992.

- MINISTRY OF PLANNING AND COORDINATION OF ECONOMIC AND SOCIAL DEVELOPMENT.

National ReconsIruction Plan, Report to the Consultative Group Meeting, Washington, D.C., March 1992.

- MINISTAY OF PLANNING AND COORDINATION OF ECONOMIC AND SOCIAL DEVELOPMENT WITH COOPERATION OF THE UNITED NATIONS DEVELOPMENT PROGRAMME (UNDP).

Priority Technical Assistance Requirements for the 1993, Report to the Consultative Group "Consolidating the Peace Through Nalional ReconsIruction and Poverty Allivialion", Consultative Group Meeting, Paris, 1 april 1993.

- MINISTRY OF PLANNING AND COORDINATION OF ECONOMIC AND SOCIAL DEVELOPMENT.

Consolidating the Peace Through National Peconstruction and Poverty Alliviation. Report to the Consultative Group Meeting, Paris, april 1993.

- Proclama de la Fuerza Armada de El Salvador, en ECA, oct.-nov. 1979, No. 372/373.

- Ruiz G., Santiago

El Proceso de Reconstrucción en El Salvador, FUNSALPRODESE, discurso, enero 1993.

- SECRETARIA DE RECONSTRUCCION NACIONAL.

Plan de Reconstrucción Nacional Iniorme de Avance a diciembre 1992, SRN, enero 1993.

- SECRETARIA DE RECONSTRUCCION NACIONAL.

Plan de Reconsirucción Nacional Informe de Avance a mayo 1993, SRN, junio 1993.

- SECRETARIA DE RECONSTRUCCION NACIONAL.

Programa de apoyo a la reinserción de los excombatientes de la Fuerza Amada de El Salvador y del Frente Farabundo Martí para la Liberación $\mathrm{Na}$ cional, SRN, julio 1992. 
- UNITED STATES GENERAL ACCOUNTING OFFICE, NATIONAL SECURITY AND INTERNATIONAL AFFAIRS DIVISION, GAONSIAD.

NGO's in Postwar Reconstruction, november 1992.

- Yariv, Danielle y Curtis, Cynthla

Afler the war: a preliminary look at the role of U.S. eld in the postwar reconstruclion of El Salvador, an Investigative report by the forelng ald monltoring project, december 1992. 